\title{
Integración de la tecnología audiovisual en la educación de personas ejecutivas: el profesorado reflexivo
}

\author{
Integrating Technology into Executive Education: The Reflective \\ Instructor
}

\section{Volumen 20, Número 2}

Mayo - Agosto

pp. 1-31

\section{Roy Campos Retana}

\section{Citar este documento según modelo APA}

Campos Retana, Roy. (2020). Integración de la tecnología audiovisual en la educación de personas ejecutivas: el profesorado reflexiovo. Revista Actualidades Investigativas en Educación, 20(2), 1-31. Doi. 10.15517/aie.v20i2.41645 


\title{
Integración de la tecnología audiovisual en la educación de personas ejecutivas: el profesorado reflexivo Integrating Technology into Executive Education: The Reflective Instructor
}

\section{Roy Campos Retana ${ }^{1}$}

\begin{abstract}
Resumen: Este ensayo científico examina la reformulación de los esquemas mentales del profesorado en los procesos de enseñanza de personas ejecutivas, mediados por la tecnología. Cada vez más, la tecnología complementa los métodos de enseñanza que tradicionalmente han liderado los programas de capacitación. Aunque el profesorado cuenta con mayores recursos tecnológicos a su disposición, enfrentan el reto de transmitir en menos tiempo la misma cantidad de contenidos. El objetivo de esta investigación es entender cómo el profesorado desarrolla sus habilidades tecnológicas para crear experiencias de aprendizaje más eficaces $y$ permanentes. Este ensayo responde a la pregunta ¿cómo aprenden el profesorado de personas ejecutivas a integrar la tecnología? La integración de la tecnología es la forma en que las capacidades y restricciones de la tecnología están incorporadas en el ejercicio profesional. Luego de explorar diversas teorías sobre el aprendizaje de personas adultas, el aprendizaje basado en la experiencia y la reflexión de las personas ejecutivas, se encontró que el profesorado debe reformular sus esquemas mentales para aprender a integrar apropiadamente la tecnología. Se concluye que la promoción de la autoconciencia en medio de la acción docente puede facilitar esta integración. Investigación futura debería abordar el uso de modelos de integración de la tecnología en el profesorado de personas ejecutivas.
\end{abstract}

Palabras clave: integración tecnológica, docentes reflexivos, educación ejecutiva.

\begin{abstract}
This scientific essay examines the reframing of instructors' mental schemas while integrates technology through executive education. While still dominant in executive education, "blackboard and chalk" delivery is increasingly being complemented by technology. Executive instructors have more technological resources at their disposal, but they face the challenge of communicating the same amount of content in less time. The objective of this research is to understand how instructors develop their technical skills to create more effective and memorable learning experiences. This essay answers the question: How do executive instructors learn to integrate technology? Technology integration is the way the technology's enablements and constraints are embedded into a practice. After exploring various theories on both adult and experience learning and reflective practitioners, it was found that instructors must reframe their mental schemas to learn how to integrate technology properly. It is concluded that the promotion of self-awareness in the midst of teaching action can enable this integration. Future research should address the use of technology integration models within executive instructors.
\end{abstract}

Keywords: technological integration, reflective instructors, executive education.

\footnotetext{
1 Profesor de la Escuela de Administración de Negocios, Universidad de Costa Rica. Master en Gobierno y Cultura de las Organizaciones, Universidad de Navarra (https://www.unav.edu); donde cursa sus estudios doctorales. Orcid https://orcid.org/0000-0001-7519-9219
}

Dirección electrónica: roy.camposretana@ucr.ac.cr

Ensayo recibido: 18 de octubre, 2019

Enviado a corrección: 2 de abril, 2020

Aprobado: 27 de abril, 2020

Los contenidos de este artículo están bajo una licencia Creative Commons 


\section{Introducción}

A corto plazo la educación presencial será cada vez menor. Según la "Business School Technology Survey", las tecnologías de la información tienen una presencia masiva en las escuelas de negocios más importantes del mundo. Por ejemplo, hay un porcentaje importante de estas escuelas que están invirtiendo en servicios de teleconferencia y en servicios audiovisuales integrados (AACSB International, 2015, p. 2). Informes sobre las tendencias de la educación y la capacitación corporativa evidencian que gran parte de las horas de formación futuras utilizarán métodos basados en tecnología, en formatos tales como la educación híbrida, el aprendizaje móvil y la modificación de los espacios del aprendizaje (Brown et al., 2020; Bryan et al., 2019; Linkedln, 2019). Aunque la modalidad de educación presencial ha bajado en comparación con años anteriores, sigue teniendo un papel importante y constituye la mitad de las horas de aprendizaje empleadas. Este mismo informe prevé que, si la tendencia a la virtualidad persiste, irá desplazando poco a poco la educación cara a cara y esta última llegará a constituir menos de la mitad de las horas de clases recibidas por ejecutivos en un futuro cercano.

Esta tendencia, lejos de restar importancia a la educación dentro del aula, le debe otorgar mayor interés. El profesorado² debería integrar la tecnología en función de los objetivos pedagógicos y de los contenidos a abarcar. Por ejemplo, tendrán que optimizar la entrega de contenidos en sus clases presenciales y hacer más efectivos sus tiempos de educación cara a cara. No es posible predecir la desaparición de la educación dentro de un aula, pero sí prever la necesidad de generar aprendizajes más perdurables y ricos en contenidos. A esto se suma la incorporación, tanto al plantel de docentes como a los grupos de estudiantes, de las nuevas generaciones de ejecutivos ("millenials", generación z), cuya familiaridad con el universo tecnológico es desafiante. Aunque este es un desafío preponderante en poblaciones estudiantiles en etapa escolar y colegial, también es un reto vigente para la educación superior y personas adultas (Aldunate and Nussbaum, 2013; Graham and Nastasi, 2015).

Esta investigación es de carácter teórico. Se analizan autores y estudios ya realizados previamente. Debido la originalidad de la pregunta de investigación planteada, se consideró conveniente integrar la literatura existente a fin de desarrollar intuiciones teóricas que pudieran ser comprobadas empíricamente en estudios ulteriores. Un componente distintivo

\footnotetext{
2 En adelante, se utilizarán indistintamente los términos profesorado y profesorado de personas ejecutivas.
} 
de esta investigación consiste en que el sujeto de estudio es el profesorado de personas ejecutivas, más que el estudiantado o la tecnología misma, de manera que todo el análisis se hará a través del prisma del profesorado y luego de su entorno.

Además de este aspecto diferenciador, existe otro valor agregado referente a la utilización de referencias a muchos autores cuya lengua original es el inglés. De este modo se acerca al lector a pensadores y a teorías poco fáciles de acceder en español, que al día de hoy cuentan con pocas traducciones al castellano, o difíciles de encontrar. No se hacen citas textuales -las traducciones son propias- y, más bien, a pie de página se recogen algunas frases para precisarlas en su lengua original.

\section{Desarrollo del tema}

\subsection{Proposición: integración de la tecnología en la educación ejecutiva.}

Este ensayo científico tratará sobre el aprendizaje del profesorado. Para ello se analizará en qué consisten la andragogía, el aprendizaje basado en la experiencia y algunos conceptos básicos relacionados con la neurociencia y la memoria. Además, se describirán los modos de aprendizaje docente de personas ejecutivas, así como los fundamentos de la reflexión profesional aplicados a la actividad docente. Este ensayo responde a la pregunta ¿cómo aprende el profesorado de personas ejecutivas a integrar la tecnología en sus aulas?

Primeramente, se abordarán los supuestos de la andragogía (disciplina que estudia el aprendizaje de adultos). Luego, se hará una revisión del comienzo de la educación audiovisual, junto con algunos de los fundamentos del aprendizaje basado en la experiencia y otros conceptos básicos relacionados con la memoria. Se expondrán los modos de aprendizaje para sugerir que docentes y ejecutivos deben armonizar ejecución y reflexión, y que esta dialéctica aparente se puede resolver con la reflexión sobre la acción docente. Todo esto será la base para sugerir una definición sobre la integración de la tecnología.

\subsection{Argumentos para la discusión.}

\subsubsection{El aprendizaje de adultos: la andragogía}

Knowles (1980, p. 43) definió la andragogía (del griego ávńp "hombre" y áywүń "guía") como el arte y ciencia de ayudar a las personas adultas a aprender; en contraste con la pedagogía (del griego maı́íov -paidíon- "niño" y áywyós -agōgós- "conducción”), que es la ciencia y arte de enseñar a la niñez. Históricamente, diversos autores hicieron uso del término andragogía y utilizaron el concepto "educación de adultos" (Rachal, 2002, p. 210); 
sin embargo, es Knowles quien lo interpreta como un término con raíces filosóficas y metodológicas.

Malcolm Shepherd Knowles se consagró al estudio de la educación de personas adultas y a su enseñanza informal en los Estados Unidos durante la segunda mitad del siglo XX. A lo largo de su labor como director de educación de personas adultas en varias universidades americanas, se ganó un reconocimiento general como teórico de la andragogía. La exposición de su pensamiento no es precisamente sistemática. No es fácil encontrar en él definiciones explícitas y ampliamente desarrolladas de los temas más relevantes (Henry, 2009) pues tiende a ofrecer muchas orientaciones prácticas para apoyar al profesorado. Pese a que la fonética de la palabra andragogía y la profundidad con que la estudia no son las deseadas por muchos académicos y educadores, sus elementos fundacionales merecen ser integrados dentro del contexto de la formación ejecutiva.

En 1980 Knowles publicó el libro The Modern Practice of Adult Education; Andragogy versus Pedagogy, el cual se revisará brevemente. Para Knowles (1980, p. 40) uno de los problemas que presentaba la pedagogía consistía en fundamentarse sobre una premisa insuficiente para el estudiantado adulto: transmitir conocimiento y habilidades que superaran el paso del tiempo. El profesorado de adultos encontraba cierta resistencia a las estrategias didácticas prescritas, tales como conferencias, lecturas, ejercicios, pruebas cortas, recitar de memoria y hacer exámenes. Las personas adultas parecían querer una cosa distinta. De hecho, las tasas de deserción de los programas para personas adultas eran cada día mayores. En consecuencia, la pedagogía, entendida como la ciencia sobre la enseñanza de la niñez, requeriría una adaptación que permitiera enseñar mejor a las personas adultas.

Con el paso del tiempo un número creciente del profesorado de educación primaria y secundaria empezaría a informar a Knowles que estaban ensayando la aplicación de conceptos de andragogía a la educación de jóvenes, quienes encontraron que en ciertas situaciones generaban un aprendizaje superior. Desde entonces, Knowles considerará que la andragogía podrá ser usada conjuntamente con los supuestos del modelo pedagógico, proveyendo así dos alternativas -pedagogía y andragogía- que tendrán que ser probadas hasta adaptarse a las diferentes particularidades. En la tabla 1, Knowles compara los supuestos de la pedagogía y la andragogía. 
Tabla 1. Comparación de los supuestos de la pedagogía y la andragogía

\begin{tabular}{|c|c|c|}
\hline $\begin{array}{c}\text { Con } \\
\text { respecto a }\end{array}$ & Pedagogía & Andragogía \\
\hline $\begin{array}{l}\text { Concepto } \\
\text { del que } \\
\text { aprende }\end{array}$ & $\begin{array}{l}\text { El rol del que aprende es, por } \\
\text { definición, dependiente. La sociedad } \\
\text { espera que el profesorado se } \\
\text { responsabilice completamente de } \\
\text { determinar qué se aprenderá, } \\
\text { cuándo y cómo. }\end{array}$ & $\begin{array}{l}\text { Lo normal es que el proceso de } \\
\text { de una persona se mueva de la } \\
\text { hacia una creciente auto-direcc } \\
\text { ritmos diferentes para distinta } g \\
\text { distintos roles en la vida. El profe } \\
\text { la responsabilidad de nutrir este c }\end{array}$ \\
\hline $\begin{array}{l}\text { El rol de la } \\
\text { experiencia } \\
\text { de quienes } \\
\text { aprenden }\end{array}$ & 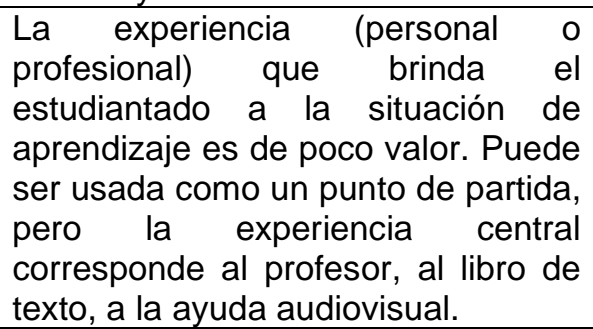 & $\begin{array}{l}\text { En la medida en que las personas adultas } \\
\text { maduran, se desarrolla un creciente depósito } \\
\text { de experiencia que se convertirá en un rico } \\
\text { recurso de aprendizaje, tanto para ellos como } \\
\text { para otros. Es más, la gente encontrará } \\
\text { mayor sentido a los aprendizajes que vengan } \\
\text { de una experiencia, que aquellos que se } \\
\text { reciban pasivamente. }\end{array}$ \\
\hline $\begin{array}{l}\text { Disposició } \\
\text { de } \\
\text { aprender }\end{array}$ & $\begin{array}{l}\text { La gente está dispuesta a aprender } \\
\text { lo que la sociedad (especialmente la } \\
\text { escuela) diga que se debe aprender, } \\
\text { poniendo presión suficientemente } \\
\text { grande en ellos, como el temor a } \\
\text { fracasar. Quienes poseen la misma } \\
\text { edad están preparadas para } \\
\text { aprender las mismas cosas. }\end{array}$ & $\begin{array}{l}\text { tareas o problemas de la } \\
\text { profesorado tiene una respor } \\
\text { crear condiciones y proveer h } \\
\text { procedimientos para ayudar a } \\
\text { necesidades de conocimiento. }\end{array}$ \\
\hline $\begin{array}{l}\text { Orientació } \\
\text { al } \\
\text { aprendizaj }\end{array}$ & $\begin{array}{l}\text { Quienes aprenden ven la educación } \\
\text { como un proceso de adquirir temas, } \\
\text { la mayoría de los cuales deben ser } \\
\text { utilizados en algún momento de la } \\
\text { vida. En la orientación de su } \\
\text { aprendizaje, la gente está centrada } \\
\text { en los contenidos. }\end{array}$ & $\begin{array}{l}\text { Las personas adultas ven la educación como } \\
\text { un proceso de desarrollar competencias para } \\
\text { lograr su potencial. Quieren que el } \\
\text { conocimiento y habilidades que adquieren } \\
\text { hoy les sirvan para vivir mejor el día de } \\
\text { mañana. En la orientación de su aprendizaje, } \\
\text { la gente está centrada en su desempeño. }\end{array}$ \\
\hline
\end{tabular}

Fuente: Adaptado de Knowles (1980, pp. 43-44)

Como es sabido, y como se ampliará más adelante al explicar los roles del profesorado y los estilos de aprendizaje, hoy día la definición de pedagogía de Knowles ha evolucionado sustancialmente. De hecho, muchas tendencias educativas y aproximaciones al aprendizaje tienen en cuenta los intereses de los estudiantes en el mundo real y existen numerosos modelos donde el rol del docente es de facilitador o de guía; por ejemplo, el aprendizaje activo (Johnson and Johnson, 2008; Meyers and Jones, 1993) y el aprendizaje auténtico (lucu and Marin, 2014; Wiggins, 2011). Para continuar con el planteamiento inicial de este ensayo, por ahora se procederá a resumir los supuestos de Knowles para el aprendizaje de los adultos en estos cuatro puntos (1980, pp. 44-45):

1. Auto-concepto: el auto-concepto del individuo se mueve de una personalidad dependiente (niñez) hacia un ser humano auto-dirigido (persona adulta); será él quien escoja las prioridades de su aprendizaje y, por tanto, qué aprender. Esto será de 
especial relevancia en el desarrollo de la memoria y de aplicación también para el profesorado: dependiendo de sus experiencias personales previas, será más propenso a innovar en su aula o no.

2. Experiencia: la persona adulta acumula un depósito de experiencia que se convierte en un recurso cada vez mayor para el aprendizaje; esas experiencias conformarán sus modelos y esquemas mentales, sus estilos de aprendizaje, que irán adaptándose a cada circunstancia de la vida. Será el profesorado quien influya en la dimensión transformadora de una experiencia para que sea educativa.

3. Disposición para el aprendizaje: su preparación para aprender se orienta cada vez más a las tareas del desarrollo de sus roles sociales; aunque Knowles no define cuáles son esos roles -él les llama categorías-, puede entenderse que se refiere al rol de estudiantado o profesorado, gerente o supervisor, por ejemplo.

4. Orientación al aprendizaje: su perspectiva del tiempo cambia de una aplicación pospuesta de conocimiento hacia una de aplicación inmediata y, en consecuencia, su orientación a través del aprendizaje cambia de una centrada en el sujeto a una centrada en el problema. El mayor problema que enfrentará el profesorado será la transformación que debe realizar de sus experiencias pasadas para aplicarlas al presente: el uso de dispositivos audiovisuales será distinto al de una pizarra tradicional, y tendrá que explorar aplicaciones antes no imaginadas.

Knowles, va más allá del estudiante: ofrece conceptos y herramientas para apoyar al profesorado. Más aún, por las diferencias con la pedagogía, se entiende que profesorado de las personas adultas -ejecutivas en este caso- debe aprovechar la experiencia acumulada de su estudiantado y conectar las experiencias dentro del aula con la realidad profesional de cada uno de ellos. El profesorado deberá acudir a diversos métodos para enseñar, los cuales implican una mayor participación y diferentes recursos didácticos, tales como los audiovisuales. Para empezar a entender lo que eso supone, se analizará el aprendizaje basado en la experiencia. 


\subsubsection{Aprendizaje basado en la experiencia}

Según Dewey (1938, p. 13), creer que toda educación auténtica viene a través de experiencias $^{3}$ no significa que todas las vivencias sean igualmente educativas. De hecho, algunas experiencias resultan educativamente fallidas cuando detienen o distorsionan el desarrollo y la experiencia futura. Para Dewey $(1938$, p. 14) una experiencia fallida es capaz de engendrar insensibilidad o puede producir una falta de receptividad. Entonces, la posibilidad de tener experiencias más ricas en el futuro se restringe. Cuando el profesorado utiliza métodos rutinarios y monótonos en su aula, inhibe el potencial del estudiantado para sucesivas ocasiones de aprendizaje.

Entonces, ¿Cómo lograr que el profesorado de las personas ejecutivas logre experiencias educativas y perdurables mediante el uso de recursos audiovisuales? En su libro Experience and Education, Dewey destaca dos principios sobre los cuales se basa el aprendizaje basado en la experiencia, que son el principio de inmediatez y el principio de continuidad. Esos ayudarán a comprender mejor el modo de utilizar los recursos audiovisuales en el aula, por parte del profesorado.

El principio de inmediatez de Dewey sugiere que es deber del profesorado disponer de experiencias que no repelan al estudiantado y que, más que ser directamente placenteras, propicien el deseo de experiencias futuras. Lejos de conectar al estudiantado con los contenidos, una vivencia en el aula puede dispersarle y hacer restar importancia a lo que se enseña, porque está esperando que le deleite, sin importar su sentido o propósito. Aquí, la energía del estudiantado se desvanece, y con él la motivación del profesorado, porque quien aprende estará atolondrado o despistado; y quien enseña, molesto o confuso.

En Dewey (1938, p. 16) la calidad de la experiencia es un rasgo fundamental, puesto que cada vivencia, para ser provechosa, depende de la calidad misma de esa experiencia. Para Dewey no hay en el aprendizaje recursos especiales, "balas de plata", que otorguen calidad a la educación. Por ejemplo, la calidad no dependerá de si se usan videos o se usa una pizarra, sino que la calidad variará de cada situación específica y de cómo el profesorado logre identificar el mejor modo de conseguirlo.

A su vez, Dewey (1938, p. 16) afirma que esa calidad debe tener una causa, la cual puede ser una institución o incluso una plataforma, como un periódico, por ejemplo. Al mismo

\footnotetext{
${ }^{3}$ Pese a que en algunas ocasiones el concepto de experiencia pueda identificarse con el de vivencia, o incluso se utilice de manera indistinta, a lo largo de estas páginas el uso de la palabra experiencia siempre se hará con una clara acepción en torno al aprendizaje, por encima de una referencia a una situación o actividad pasajera y efímera.
} 
tiempo, esa causa tendrá un efecto, pero ese efecto no se verá en el momento mismo en que sucede la experiencia particular, sino que se va a acumular en el futuro, y esto es lo que constituye un aprendizaje. En otras palabras, usar un recurso audiovisual puede constituir la causa de un aprendizaje, pero ese aprendizaje no tendrá un efecto en el aula misma, sino que se acumulará en el estudiante para ser aprovechado en situaciones futuras. Aquí es donde el principio de inmediatez conecta con el siguiente principio, el de continuidad.

El principio de continuidad (Dewey, 1938, pp. 23-28) consiste en discriminar entre las experiencias valederas durante la educación, de aquellas que no lo son. Las experiencias generan hábitos, interpretados estos biológicamente. La característica básica de un hábito así entendido es que toda experiencia está modificando a quien actúa, al tiempo que esta modificación afecta, lo queramos o no, a la calidad de las experiencias subsiguientes. Una persona es distinta antes y después de atravesar una vivencia. Un hábito es algo distinto que una costumbre, aunque a veces puede presuponerlo. Un hábito es una acumulación de vivencias, que pueden ser discriminadas unas de otras. Cuando se capta el modo en que un hábito opera, es cuando el principio de continuidad actúa.

Es ahora cuando amerita entender mejor el modo en que se acumulan esas experiencias y las maneras en que el profesorado las va convirtiendo en un capital de recursos para ser utilizados en situaciones futuras. Esas experiencias se acumulan en la memoria y es en ella donde dichas vivencias irán formando ciertos esquemas mentales, los cuales habilitarán o restringirán el modo en que pueda enfrentar nuevas situaciones de aprendizaje como, por ejemplo, el uso de recursos audiovisuales.

\subsubsection{Neurociencia: memoria y esquemas mentales.}

Sousa (2011, p.78) define la memoria como el proceso por el cual se conservan los conocimientos y las habilidades para el futuro. En otras palabras, el conocimiento del pasado se aprende y se acumula en la memoria para su uso posterior. De hecho, existe literatura abundante que ha demostrado cómo la memoria afecta al aprendizaje futuro. Para explicarlo con cierto detenimiento, se harán algunas distinciones sobre los tipos de memoria, relevantes para este proyecto.

En primer lugar, para entender el aprendizaje debemos distinguir memoria a corto y a largo plazo. Según Zull (2002), la memoria a corto plazo (o memoria de trabajo) se utiliza para realizar una tarea, más que como una fuente de información. Funciona cuando se recuerda la información que se necesita usar para una tarea y cuando se culmina, se 
descarta toda aquella información que no resulta necesario almacenar. Más importante para este estudio es la memoria a largo plazo. Según Zull (2002, p.78) la memoria a largo plazo es esa mezcla de sentimientos y hechos que nos permite recordar -o más exactamentereunir la información que viene de los aprendizajes a lo largo de la vida. En la memoria de largo plazo los recuerdos se pueden dividir en dos categorías: aquellos de los que somos conscientes (memoria explícita) y aquellos de los que no lo somos (memoria implícita). La comprensión de lo que se aprende está fuertemente influida por ambos.

Por ejemplo, un profesor que enseña finanzas mediante uso de casos, puede estar acostumbrado a organizar su análisis mediante el uso de video proyector. En la medida en que repita este sistema a lo largo de los años, lo irá consolidando cada vez más, de manera que cuando reciba otro caso, es posible que aplique de manera fluida ese mismo modo de proceder. Es decir, cada vez que enfrente un caso nuevo, lo tratará de adaptar a ese esquema preestablecido. De hecho, al inicio quizá se preparaba de una manera meticulosa para desarrollar cada caso, pero con el tiempo lo hará de manera más espontánea, incluso inconsciente, si se quiere llamar así. Ahora bien, cuando ese profesor enfrente la posibilidad de resolver casos mediante el uso de pizarra, de manera inconsciente tratará de encajarlos dentro de su esquema anterior. Esto sucede porque en su memoria de largo plazo no hay aprendizajes que le lleven a actuar de otro modo.

Para entender mejor en qué consiste la memoria implícita puede ser de utilidad recordar la célebre frase de Polanyi "we can know more than we can tell" (1966, p. 4); es decir, podemos conocer mucho más de lo que estamos en capacidad de decir o explicar. A esto Polanyi lo definirá como conocimiento tácito. Una manera de ejemplificar este tipo de conocimiento es la anécdota que contaban de San Agustín, cuando le consultaban cómo definir el tiempo, decía: "Si nadie me lo pregunta, lo sé; si me lo preguntan y quiero explicarlo, ya no lo sé." Seguramente tendría una noción filosófica del tiempo más profunda y elaborada que muchos pensadores, pero no siempre es posible explicar todo lo que se sabe.

Algo parecido sucede en el aprendizaje del profesorado, porque la memoria implícita se ubica en la memoria de largo plazo: el modo de resolver casos de finanzas se ha convertido en conocimiento tácito, el modo de usar recursos audiovisuales se ha convertido en conocimiento tácito. El modo de dictar clases se ha vuelto implícito, y si le preguntáramos a un profesor por qué lo ha hecho de esa manera y no de otra, quizá ofrecería una respuesta limitada, a pesar de su pericia para enseñar. 
En segundo lugar, existe un proceso llamado transferencia o transformación (Sousa, 2011; Zull, 2002), que permite al profesorado explicitar algunos recuerdos de aprendizaje, permitiendo entonces mejorar su práctica en situaciones posteriores. Este fenómeno tiene dos dimensiones. El primero es el efecto del aprendizaje pasado en la adquisición de nuevos aprendizajes: hay una transformación o transferencia del conocimiento pasado a situaciones futuras. La segunda parte del proceso de aprendizaje es el grado en que el profesorado aplica un nuevo aprendizaje a situaciones futuras: consiste en la introversión del conocimiento externo a través de la reflexión, de manera que los individuos pueden convertirse en creadores activos de nuevos conocimientos.

A esto Sousa añade que la práctica, el ensayo ${ }^{4}$, es un proceso esencial en la transferencia de información desde la memoria de trabajo hasta el almacenamiento a largo plazo. Por tanto, integrar las tecnologías en el aula quizás sea más difícil para el profesorado maduro, que para sus colegas más jóvenes: desarrollar nuevos esquemas mentales será más fácil para aquel profesorado de personas ejecutivas que han estado menos expuestos a la práctica de nuevas tecnologías 5 .

En cuarto lugar, el aprendizaje consiste en transformar y crear nuevos conocimientos. Dewey (1938, pp. 47-48) sostiene que es un error suponer que la adquisición de destrezas en lectura y cálculo constituirá automáticamente la preparación para su uso correcto y efectivo en condiciones muy distintas a las que se adquirieron. En consecuencia, el profesorado sólo podrá aprovechar las posibilidades de la tecnología y gestionar sus limitaciones, siempre y cuando aprendan a manejar sus conocimientos tácitos.

A propósito de lo anterior Zull (2002, p.79) afirma que la distinción entre memoria explícita y memoria implícita tiene muchas implicaciones para un profesor. Los comportamientos, las creencias y los sentimientos pueden almacenarse en la memoria implícita, por tanto, cuando se quiere ayudar a alguien a aprender se deben tomar tales elementos en consideración, al igual que aquellos aprendizajes que se recuerda de manera explícita. La gente puede saber más de lo que puede decir, como afirmaba Polanyi.

Las nuevas tecnologías requerirán la elaboración de nuevos esquemas mentales y creencias para hacer frente a situaciones desconocidas. Hacerlo requerirá reflexión para

\footnotetext{
${ }^{4}$ En inglés "rehearsal".

${ }^{5}$ A esto se puede añadir otro concepto que es el de neuroplasticidad (Goh and Park, 2009), entendida como la capacidad de adaptación del cerebro para responder y adaptarse a circunstancias cambiantes, y que en adultos puede mirarse como una respuesta compensatoria a los cambios del cerebro propios de la edad. Por tratarse de un área propia de la neurobiología, más afín a las ciencias, no se tratará en este estudio.
} 
explicitar el depósito de conocimiento almacenado en la memoria. Así lo aborda Ertmer (2005) cuando se refiere a las funciones cognitivas, sociales y afectivas: el profesorado debe someter a examen sus valores y creencias pedagógicas más arraigados, para enfrentar el desafío de la integración tecnológica. Autores relevantes tales como Pajares (1992) y Nespor (1987) abordaron desde el siglo pasado la construcción de estas estructuras sociales, que a su vez pueden convertirse en barreras. No obstante, cada vez existen más aproximaciones al problema de la integración tecnológica, que se vuelven más vigentes conforme avanzan las invenciones educativas con el uso de recursos multimedia, presenciales o virtuales (Ertmer, Ottenbreit-Leftwich, Sadik, Sendurur, and Sendurur, 2012; Ertmer, 1999).

La intensidad y la extensión de los ensayos anteriores actuarán como un antecedente crucial de la integración tecnológica. Para complementar lo visto hasta ahora, se estudiará a David Kolb, quien analiza el aprendizaje de docentes, basándose en evidencias. Para Kolb las transacciones del individuo con su entorno definen el estilo de aprendizaje. Es decir, no basta afirmar que el profesorado "es así" o que, al ser ingeniero en sistemas, tendrá mayores facilidades para integrar la tecnología.

Lo que afirmará Kolb es que, sin descuidar esos aprendizajes pasados, lo que define el aprendizaje presente es la relación con el entorno y los individuos que le rodean. Un profesor de un programa de MBAs, o una profesora de personas ejecutivas dentro de una empresa, presentarán estilos de aprendizaje similares, indistintamente si son ingenieros, filósofos, o matemáticos. Esto parece paradójico, pero los estudios de Kolb permiten demostrar que el profesorado, también el de personas ejecutivas, tienden a presentar rasgos similares: propondrá que presentan una dialéctica entre la reflexión y la ejecución.

\subsubsection{Estilos de aprendizaje del profesorado}

Kolb procura relacionar a varios referentes en educación, tales como John Dewey, Jean Piaget y Kurt Lewin, e identifica las características comunes que comparten, para definir la naturaleza del aprendizaje basado en la experiencia. De hecho, usando como base el proceso de aprendizaje de Lewin (ver figura 1), Kolb construirá su modelo de cuatro etapas (experiencia, reflexión, abstracción y prueba), y definirá el aprendizaje como el proceso por el cual el conocimiento es creado a través de la transformación de la experiencia $^{6}$ (1984, p. 38). Ahora se procederá a explicar algunos aspectos de ese modelo.

\footnotetext{
6 "Learning is the process whereby knowledge is created through the transformation of experience" (D. A. Kolb, 1984, p. 38)
} 
Figura 1: Modelo de aprendizaje experiencial de Lewin

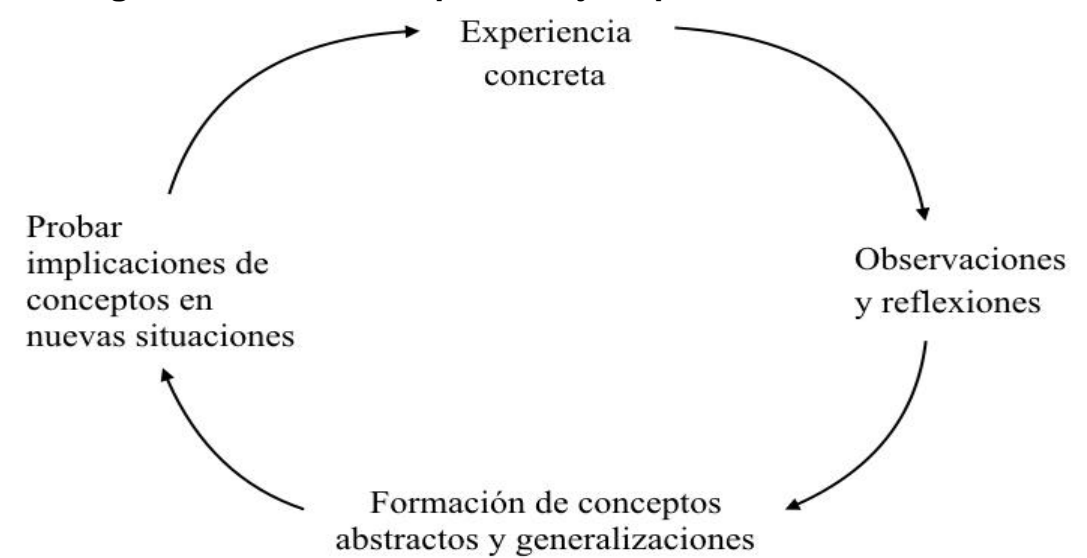

Fuente: Adaptado de Kolb (1984, p. 21)

Para Lewin, las observaciones y reflexiones se hacen a partir de la experiencia concreta (D. A. Kolb, 1984, p. 21). Estas observaciones se asimilan en una "teoría" desde la cual se pueden deducir nuevas implicaciones para la acción. Estas implicaciones o hipótesis entonces sirven como guías en la actuación para crear nuevas experiencias. Es decir, en Lewin, teoría y práctica van de la mano. De su modelo de aprendizaje son particularmente dignos de mención dos aspectos.

En primer lugar, el énfasis en la experiencia concreta aquí y ahora para validar y probar conceptos abstractos (D. A. Kolb, 1984, p. 21). La experiencia personal inmediata es el punto focal para el aprendizaje, dando vida, textura y significado personal subjetivo a los conceptos abstractos, y al mismo tiempo proporcionando un punto de referencia concreto -y compartido públicamente- para probar las implicaciones y la validez de las ideas creadas durante el proceso de aprendizaje. En cuanto a este primer punto, se puede explicar diciendo que cada persona genera "teorías" a partir de sus aprendizajes pasados, las cuales valida mediante las experiencias concretas. Estas vivencias concretas tienen a su vez implicaciones grupales, sociales o públicas.

En segundo lugar, los procesos de retroalimentación (D. A. Kolb, 1984, p. 22). Lewin y sus seguidores creían que la gran ineficacia individual y organizativa se debía a la falta de procesos de retroalimentación adecuados. Esta ineficacia es el resultado de un desequilibrio entre la observación y la acción, ya sea por la tendencia de los individuos y las organizaciones a enfatizar la decisión y la acción, o bien por la tendencia a quedar paralizados debido a la recolección y análisis de datos. El objetivo del método de investigación de Lewin es integrar estas dos perspectivas -observación y acción- en un 
proceso de aprendizaje eficaz y orientado a metas. Recuérdese que Lewin es el autor de la célebre frase "There is nothing so practical as a good theory": no hay nada más práctico que una buena teoría. Esa expresión tan difundida puede ayudar a entender su enfoque teóricopráctico.

A partir del modelo experiencial de Lewin, y relacionándolo con el de otros autores, Kolb (1984, pp. 68-69) propone que el proceso de aprendizaje basado en la experiencia puede ser descrito como un ciclo que implica cuatro modos básicos de aprendizaje (ver figura 2). Cada uno de estos modos explica la orientación del aprendizaje que poseen los individuos, a saber:

1. Una orientación a través de la experiencia concreta (verbo de ejemplo: sentir). Esto implica vivir experiencias y enfrentar situaciones humanas de manera directa y personal. Las personas con esta orientación disfrutan al relacionarse con otros, al estar envueltas en situaciones reales y tienen una mente abierta hacia la vida.

2. Una orientación hacia la observación reflexiva (verbo de ejemplo: observar). Se enfoca en entender el significado de las ideas y de las situaciones mediante la observación y las describe objetivamente. Las personas con esta orientación disfrutan intuyendo el sentido de situaciones e ideas, miran las cosas desde perspectivas diferentes, confían en sus pensamientos, valoran la paciencia y el juicio meditado.

3. Una orientación mediante la conceptualización abstracta (verbo de ejemplo: pensar). Se enfoca en usar la lógica, ideas y conceptos. Las personas con este perfil son buenas en la planificación sistemática, manipulación de símbolos abstractos y análisis cuantitativo. Valoran la precisión, el rigor y la disciplina en el análisis de las ideas y aprecian la calidad estética de un cuidado sistema conceptual.

4. La orientación a través de la experimentación activa (verbo de ejemplo: hacer). Se enfoca en influenciar activamente a la gente y cambiar situaciones. Este tipo de personas disfrutan haciendo que las cosas sucedan, desean enfrentar riesgos para alcanzar objetivos, valoran influir en su entorno y les gusta ver resultados.

Llegados a este punto, surge la siguiente inquietud: el profesorado de ejecutivos, ¿con qué estilo de aprendizaje se identificaría: experiencia concreta, observación reflexiva, conceptualización abstracta o de experimentación activa? En Kolb (1984, p. 61 ss) estos cuatro modos permitirán producir una rica diversidad de procesos de aprendizaje que 
variarán ampliamente en sutileza y complejidad, pero no serán los mismos para todos los individuos. Los llamará estilos de aprendizaje?

Figura 2: Estructura del aprendizaje experiencial y las formas del conocimiento

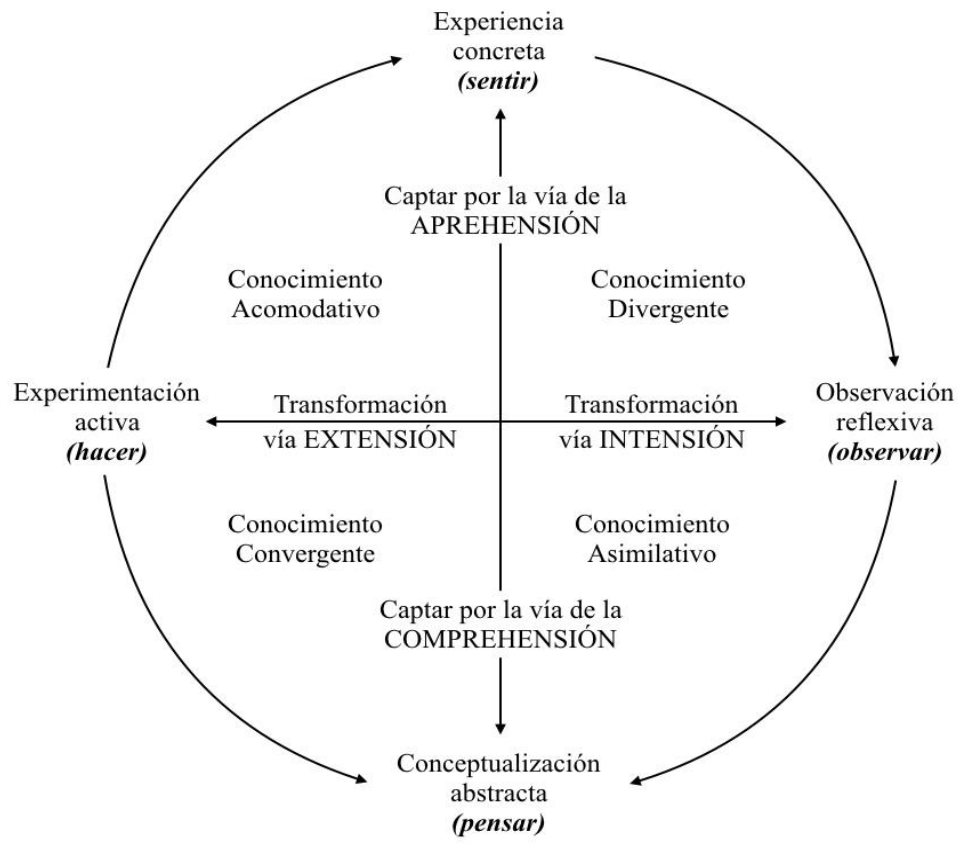

Fuente: Adaptado de Kolb, D. (1984, p. 42)

Basado en estudios empíricos, Kolb muestra que la estructura del conocimiento de los académicos y de los estudiantes son más propias de la reflexión, mientras que aquellas que corresponden a los ejecutivos son más propias de la acción (1984, pp. 121-131). En efecto, la investigación sobre los estilos de aprendizaje ha demostrado que las personas que desempeñan cargos gerenciales, en general, se distinguen por unas habilidades de experimentación activa fuertes y por unas habilidades de observación reflexiva más débiles. En cambio, el profesorado de negocios (y el profesorado en general) suelen tener el perfil inverso (A. Y. Kolb and Kolb, 2011a). Además de eso, utilizando una muestra de 1.286

7 "Learning Styles Inventory": L.S.I. por sus siglas en inglés. Por motivos de síntesis, las vías de captación y transformación, así como los tipos de conocimiento, aunque interesantes, no se abordarán en este trabajo de investigación. Para efectos de este estudio bastará entender la distinción y complementariedad entre reflexión y experimentación. A esta última le llamaremos ejecución. 
estudiantes de MBA, Kolb encuentra que el estudiantado de MBA son una mezcla de acción y reflexión (A. Y. Kolb and Kolb, 2005, p. 202) ${ }^{8}$.

A esa tensión entre la ejecución y la reflexión, Kolb llamará "dialéctica", porque incluye modos de aprendizaje opuestos. La aparente paradoja que afecta al sujeto de este estudio reside en que el profesorado de personas ejecutivas suelen ser profesionales en activo, aun y cuando realicen investigación: no puede obviar su formación y dinámica profesional. Los roles de personas de la academia y personas ejecutivas -Knowles les llama categoríascoinciden en un mismo individuo, que se verá obligado a armonizarlos; por ejemplo, a relacionar clases, proyectos, consultorías, viajes e investigaciones. Por tanto, se puede proceder a formular la siguiente propuesta teórica: el profesorado de personas ejecutivas, es un híbrido entre la ejecución y la reflexión.

Así, por ejemplo, David y Alice Kolb crean el "Perfil de los Roles del Educador" (A. Y. Kolb and Kolb, 2011b, p. 36). Su finalidad es ayudar al profesorado a entender su estilo preferido de enseñanza, a planificar cómo pueden adaptarse a esos estilos de enseñanza, y cómo ajustarse a los distintos roles que desea asumir en relación con sus estudiantes. Un "rol" es un patrón de comportamientos que emergen como respuesta al ambiente de aprendizaje, incluyendo a los estudiantes y a las demandas de las tareas: no es algo estático, sino dinámico. En la figura 3, pueden mirarse los rasgos propios de cada rol.

8 Este estudio titulado "Learning Styles and Learning Spaces: Enhancing Experiential Learning in Higher Education" (A. Y. Kolb and Kolb, 2005) muestra también la relación de esos estilos de aprendizaje con los espacios del cerebro (neurociencia). 
Figura 3. Roles del profesorado y sus estilos de aprendizaje Enfocado en el estudiante

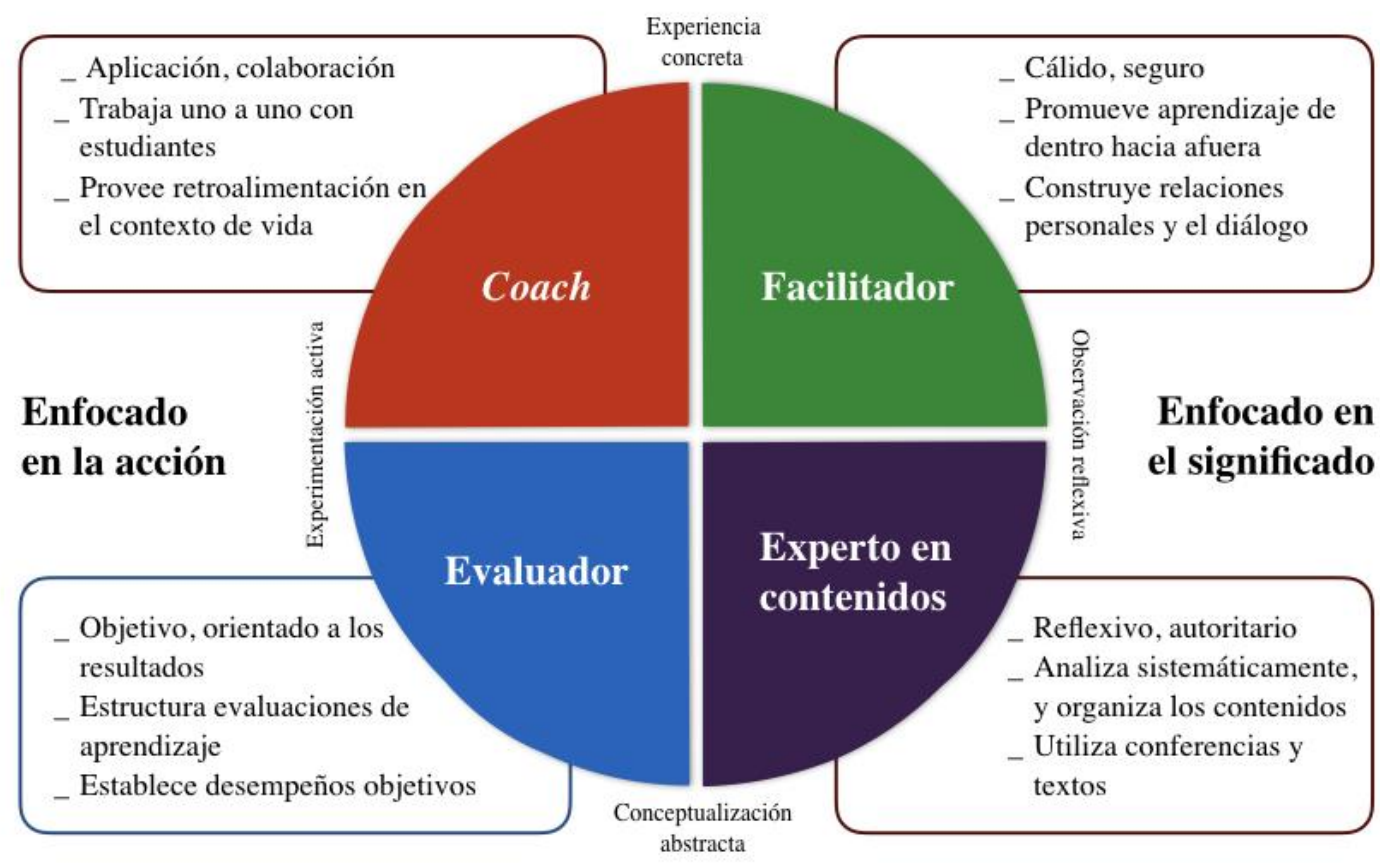

\section{Enfocado en los contenidos}

Fuente: Adaptado de "The Kolb Learning Style Inventory 4.0: Guide to Theory, Psychometrics, Research y Applications" (A. Y. Kolb and Kolb, 2011b, p. 37)

Según Kolb y Kolb (2011b, p. 37), estos son los cuatro tipos de roles:

1. Rol de Facilitador. Cuando el profesorado asume este rol, ayudan a los estudiantes a estar en contacto con su experiencia personal y a que reflexionen sobre ella. Adoptan un estilo cálido y seguro para extraer de sus estudiantes los intereses, la motivación intrínseca y el auto conocimiento. Usualmente, lo hacen facilitando la conversación en pequeños grupos. Crean relaciones personales con el estudiantado.

2. Rol del Experto. En este rol, el profesorado se desempeña como expertos en contenidos. De esta manera, ayudan a los estudiantes a organizarse y a conectar sus reflexiones con el conocimiento que fundamenta los temas que están estudiando. Adoptan un estilo reflexivo y autoritario. Usualmente enseñan con el ejemplo, modelando y estimulando el pensamiento crítico, al mismo tiempo que organizan y analizan sistemáticamente los contenidos. Este conocimiento usualmente se transmite mediante conferencias y textos.

3. Rol de Evaluador. En su condición de quien fija estándares, este perfil de profesor ayuda a los estudiantes a dominar la aplicación de conocimientos y habilidades en 
función de los requerimientos del desempeño. Adopta un estilo de orientación a los resultados objetivos, al tiempo que establece los requerimientos de conocimiento necesarios para un rendimiento apropiado. Crea actividades para que el estudiantado pueda evaluar el desempeño de su aprendizaje.

4. Rol de Coach. En este rol el profesorado ayuda a los estudiantes a aplicar el conocimiento para alcanzar sus metas. Adopta un estilo donde alienta y colabora, usualmente trabajando uno a uno con los individuos para ayudarles a aprender desde experiencias en su contexto de vida. Asiste a la creación de planes de desarrollo personal y provee formas de recibir retroalimentación del desempeño.

En resumen, experiencia y acción constituyen el modo de aprendizaje del profesorado. En consecuencia, Kolb considera que debe responder a las exigencias prácticas de pertinencia y aplicación del conocimiento, y a la vez promover la experiencia reflexiva, que es necesaria para perfeccionar viejas teorías y construir otras nuevas (A. Y. Kolb and Kolb, 2011a). La reflexión es una condición indispensable para lograr un adecuado uso de los nuevos modelos mentales en la práctica docente de personas ejecutivas. Esta cualidad es la que les permitirá sustituir o complementar las metodologías ya aprendidas (método del caso, uso de la pizarra, o presentaciones) por otras nuevas en un todo integrado.

Reformular los esquemas mentales es un proceso interno que no es fácil de articular, de comunicar y explicitar, por eso la reflexión es también necesaria en la educación ejecutiva. De hecho, tal y como explica Daudelin (1996), la educación ejecutiva desarrolla habilidades reflexivas, ejercidas generalmente mediante la solución de problemas mediante el método de caso u otras disciplinas como el "coaching". Ahora bien, ese mismo potencial de reflexión deberá ser utilizado para integrar la tecnología en el aula. Para comprender mejor cómo la reflexión es capaz de mejorar las capacidades docentes del profesorado, se utilizará como base a Donald Schön, quien estudió la capacidad de reflexión de las personas ejecutivas durante su ejercicio profesional.

\subsubsection{El profesorado reflexivo}

Según Donald Schön en su libro The Reflective Practitioner (1983, pp. 236-237), el campo de la gestión y administración de empresas ha estado históricamente marcado por el conflicto entre dos enfoques competitivos del conocimiento organizativo. En el primer enfoque, el gerente es un técnico cuya práctica consiste en aplicar al día a día de su 
organización los principios y métodos derivados de la ciencia de la gestión. En el segundo enfoque, el manager es un artista, un profesional del arte de la gestión que no puede reducir lo explícito a reglas y tareas. El primero nos sitúa frente a una persona más orientada a la acción y es el que ha ido ganando gradualmente mayor difusión; el segundo perfila a un profesional que es una amalgama de destreza y sabiduría, un individuo más reflexivo, tal y como se ha mencionado antes.

De Déa Roglio y Light (2009, p. 157) resumen la reflexión como un rasgo esencial para el desarrollo profesional artístico, entendido éste como la capacidad de dar sentido a situaciones inciertas, únicas o conflictivas de práctica profesional. En Schön esta práctica reflexiva se basa en tres conceptos: conocimiento-en-acción, reflexión-en-acción y reflexiónsobre-la-acción. El conocimiento-en-acción es una acción espontánea que se da en el día a día. Puede darse cuando las personas profesionales aprenden cómo hacer algo y son capaces de ejecutar tranquilamente secuencias de actividades, así como reconocer, decidir y hacer ajustes sin tener que gastar energía consciente pensando en ello. Desafortunadamente, y tal como se dijo a propósito de las personas ejecutivas y a quienes les educan, el día a día les suele sorprender con experiencias imprevistas, llevándolos a actuar sin la debida reflexión.

Schön (1983, p. 54) detalla las cualidades del conocimiento-en-acción ${ }^{9}$, de las cuales se anotan:

1. Hay acciones y juicios que sabemos cómo manejar espontáneamente; no tenemos que pensar en ellos previamente o durante su desempeño.

2. Usualmente no somos conscientes de haber aprendido a hacer estas cosas: simplemente nos encontramos haciéndolas.

3. En algunos casos, fuimos conscientes cuáles fueron los razonamientos internalizados en nuestra sensación de la acción misma. En otros casos, no debemos haber sido conscientes de ello. Sin embargo, en ambos casos, somos incapaces de describir el saber que nuestra acción revela.

Schön sostiene que si el sentido común es capaz de reconocer el conocimiento-enacción, estamos entonces frente a otro tipo de conocimiento: la reflexión-en-acción $n^{10}$. No es solamente ser conscientes de que estamos conociendo (a esto se suele llamar meta-

\footnotetext{
9 En inglés "knowledge-in-action".

10 En inglés "reflection-in-action".
} 
cognición), sino al proceso de hacer cambios, tomar decisiones, realizar ajustes sobre algo que estamos ejecutando. Cuando un profesor intenta responder una pregunta de un estudiante, pero percibe que la explicación que ofrece no está siendo entendida, por ejemplo: en ese mismo instante decide usar otro ejemplo u otro modo más asequible a la realidad de quienes le escuchan. En ese instante hay reflexión-en-acción.

\subsubsection{Reformulación de esquemas mentales}

Para ilustrar la formulación del conocimiento tácito pueden ser de utilidad los estudios realizados por Stephen Barley $(1986,1990)$, cuyas investigaciones demuestran cómo la incorporación de equipos de resonancia magnética dentro dos departamentos de radiología alteró la jerarquía social establecida. El conocimiento necesario para operar los equipos de resonancia magnética fue transmitido mediante una instrucción técnica explícita. En cambio, la interpretación de rayos $X$ era una destreza que se iba formando por la experiencia de leer placas a lo largo de los años, un tipo de conocimiento artístico, como explicaba Schön.

Barley $(1986,1990)$ continúa detallando que los profesionales en radiología más jóvenes, que poseían el conocimiento pertinente de cómo operar los equipos de resonancia magnética e interpretar sus reportes, fueron capaces de emitir diagnósticos más rápidos y precisos debido a un mayor detalle y claridad en las imágenes emitidas por los dispositivos. En consecuencia, los profesionales en radiología de mayor trayectoria, carentes de los conocimientos pertinentes, no lograron integrar la nueva tecnología. Esta diferencia pudo haberse debido a que el entrenamiento previo que todos recibieron se enfocó en el manejo técnico de los equipos, no tanto en la elaboración del diagnóstico, como consecuencia del manejo de esos equipos. Como resultado de la integración de la tecnología, los profesionales en radiología más experimentados se vieron expulsados de la parte superior de la jerarquía establecida y fueron reemplazados por radiólogos menos expertos, ahora especialistas en tecnología. Los roles sociales -Knowles le llama categorías- cambiaron.

Los profesionales en medicina experimentados aplicaron a la tecnología nueva los mismos esquemas mentales que funcionaban con la tecnología anterior. La aplicación de esos esquemas mentales debió cambiar cuando las situaciones se modificaron; sin embargo, se requería una reformulación. En esos momentos, la mente, la memoria, requería desaprender lo aprendido y aprender cosas nuevas. Para que esto sucediera debía haber un 
nivel de autoconciencia ("self-awareness") que suscitara la reflexión-sobre-la-acción $n^{11}$. En ese momento se podría explicitar el proceso de reformulación de esquemas mentales. En el caso de los profesionales más maduros, esta labor es más difícil, porque se han ejercitado más veces en una tarea, y por tanto la fijación de conocimientos tácitos es mayor que en la de profesionales más jóvenes.

Las tecnologías audiovisuales exigen una transformación de los conocimientos antiguos para aprovechar las ventajas y limitaciones de la tecnología. En el caso de la integración en la educación de personas ejecutivas, se puede inferir que el profesorado de mayor trayectoria, con preparación mayor a la del profesorado más joven, presentarán similares patrones de comportamiento. El profesorado más experimentado ha estado trabajando varios años utilizando los métodos tradicionales (pizarra, tiza, presentaciones sencillas); y para integrar la nueva tecnología deben desaprender la forma en que solían dictar clases, así como los métodos para enseñar, a fin de desarrollar nuevos esquemas mentales. Eso quiere decir desechar algunos esquemas, reformular otros y desarrollar unos nuevos, para enfrentar situaciones inciertas.

Daudelin (1996, p.39) explica la transformación a través de la reflexión de esta manera: cuando una persona reflexiona, toma una experiencia del mundo exterior, la trae a la mente, le da un giro, hace conexiones con otras experiencias y las filtra a través de sesgos personales (esto se definió anteriormente como transferencia o transformación). Si este proceso resulta en aprendizaje, entonces el individuo desarrolla inferencias para acercarse al mundo externo de manera distinta a la que habría utilizado si no hubiese reflexionado. Por tanto, la reflexión ocurre en la medida en que el catalizador sea externo, y que otros puedan ayudar en el proceso escuchando, haciendo preguntas, u ofreciendo consejo. En efecto, Schön considera que esto puede aplicarse perfectamente a la relación de los supervisores con sus aprendices, al profesorado con su estudiantado (1983, pp. 126-127). Más adelante se sostendrá que los modelos de integración tecnológica también ayudarán a transformar esos esquemas mentales.

Para Schön la reflexión es un proceso tan complejo como la dimensión del problema. El "pitcher" de béisbol no puede detenerse a reflexionar sobre el modo en que está lanzando, porque entorpecerá su trabajo o incluso se equivocará. Lo mismo que un músico o una profesora. La reflexión-en-acción la han hecho al entrenar, al ensayar, y la reflexión-sobre-laacción la realizarán durante el calentamiento o tras el partido. Si un jugador de fútbol se

${ }^{11}$ En inglés "reflection-on-action". 
detiene a reflexionar sobre el mejor modo de rematar para anotar un gol es posible que le quiten el balón. Lo mismo experimenta alguien que ocupe una posición gerencial, un individuo que toma decisiones, o incluso al profesorado que trata de resolver un problema con sus estudiantes.

Para Schön (1983, p. 331) la influencia del profesorado sobre sus estudiantes se supone que estará ampliamente determinada por las fronteras del plan de estudios. Se preocupa por el alumnado desde el punto de vista de su éxito o fracaso relativo en la asimilación de los materiales de un plan de clases. De modo que cuando la tecnología entra a la institución educativa, su función es extender su capacidad de transmitir los elementos del plan de estudios. Computadoras, películas, y aparatos audiovisuales son diseñados para complementar el trabajo del profesorado en la comunicación, evaluación, profundización y práctica.

Lo propuesto por Schön es coherente con las características ofrecidas por Kolb sobre la observación reflexiva, cuando sostiene que las personas con este perfil dan significado a ideas y situaciones, confían en sus pensamientos e intuyen su sentido. Lo propuesto por Schön es también coherente con el conocimiento tácito que se almacena en la memoria de largo plazo. También está alineado con el modo de aprender de los adultos, en la medida en que sus roles cambian y su orientación hacia el aprendizaje toma una importancia inmediata a la realidad que están enfrentando en el momento presente de sus vidas. De igual manera, lo propuesto por Schön permite complementar a Dale: existen aprendizajes que, sin proponérnoslo es posible recordar, pero hay otros que son igualmente perdurables, aunque no podamos recordar de manera explícita. Finalmente, la propuesta de Schön también permite profundizar en lo sugerido por Dewey: la continuidad en el aprendizaje requiere transformar conocimientos presentes para afrontar los futuros, similares a los que ofrece la tecnología. La reflexión, por tanto, es una vía sólida para enseñar al profesorado de ejecutivos a integrar apropiadamente la tecnología actual y futura.

Para Argyris y Schön (1996, p. 11) hay dos tipos de teorías que gobiernan las acciones: de una parte está la teoría defendida o teoría propuesta ${ }^{12}$; y por otro lado, la teoría en uso $^{13}$ o teoría en acción. Cuando se le pregunta a alguien cómo se comportaría bajo ciertas circunstancias, la respuesta que suele dar es su teoría propuesta para esa situación. Ésta es la teoría de aquella acción a la que es leal y que se comunica a los demás. Sin

\footnotetext{
12 En inglés, "espoused theory".

13 En inglés, "theory-in-use".
} 
embargo, la teoría que realmente gobierna sus acciones es su teoría en uso, que en ocasiones es compatible con su teoría propuesta; más aún, sólo en ocasiones es consciente de la incompatibilidad que puede darse entre ambas teorías. Algo similar sucede en educación ejecutiva: aunque el profesorado y las personas ejecutivas afirmen que utilizan la tecnología, no siempre la integran debidamente.

En apariencia se trata de una leve inconsistencia. Sin embargo, esta incoherencia se complica cuando la actitud de un profesor se generaliza a todo un claustro, o incluso se globaliza al sector de la educación ejecutiva, hasta convertirse en una dolencia generalizada: de hecho, son pocas las personas conscientes de la incoherencia entre lo que dicen y piensan, y lo que en realidad hacen de manera explícita. El inconveniente de esto radica en que, al no tener auto-conciencia de las proposiciones que utilizan, diseñan por sí mismos supuestos internos que no corrigen o, dicho en términos de innovación educativa, actúan bajo supuestos personales que inhiben la creatividad. De esta manera, el profesorado, personas listas y bien preparadas, se convierten en prisioneros de sus propias teorías.

Argyris (1977, p. 117) se pregunta: ¿Por qué las organizaciones parecen ser menos eficaces a medida que la tecnología que usan se vuelve más sofisticada? En su opinión, la respuesta consiste en que la teoría subyacente a esa nueva tecnología es la misma que creó el problema a su inicio, sin cambio. Explicándolo, por otra parte, con los conceptos de Schön, bastaría decir que los esquemas mentales erróneos que se aplicaron a las tecnologías anteriores, son los mismos que se están aplicando a las nuevas tecnologías. Antes se explicó el conocimiento tácito y la necesidad de hacer explícita esa complejidad, para reformular los esquemas mentales con que se suele incorporar la tecnología. Entonces se partió de un supuesto: que el profesorado experto utiliza la tecnología aplicando los mismos esquemas mentales con que se desempeñaban antes de tenerla. Ahora Argyris (1977, p. 119) propone que se está ante a un planteamiento complementario: el profesorado dice integrar la tecnología (teoría defendida), pero en la realidad no lo hace.

A esto se añade que para Shulman (1986, p. 7) la distinción entre pedagogía y contenidos es reciente. Antes, el profesorado competente era aquel que poseía un alto dominio de los contenidos. Luego, como un movimiento pendular, se pasó a identificar al profesorado competente con alguien que hacía buen uso de los métodos pedagógicos. Lamentablemente, ese péndulo se llevó a un tercer destino: la tecnología. Es decir, se ha pasado de ver al profesorado como especialista en contenidos o en pedagogía, a un especialista en tecnología. Para Shulman el problema de este enfoque es que cada una de 
esas especializaciones va en detrimento de la anterior, en lugar de complementarse o fortalecerse. En otras palabras, quien se especializó en el manejo de recursos pedagógicos descuidó el dominio de los contenidos, y quien hoy se especializa en la tecnología, descuida el dominio de los contenidos y de la pedagogía. En resumen, hoy día la crisis de la integración se debe al énfasis en la tecnología, con preeminencia ante la pedagogía y la entrega de los contenidos.

Usando de referencia a Lewin, puede decirse que con las nuevas tecnologías se están probando teorías viejas, las cuales poseen limitantes, y como se carece de un adecuado proceso de "feedback", no se están corrigiendo esas viejas teorías. Según Ambrose (2010), el buen "feedback" debe estar bien dirigido para que se mejore el aprendizaje del estudiantado, y se podría añadir lo mismo sobre el profesorado. De lo contrario, se agudizan las restricciones de las viejas teorías y, por consiguiente, las tecnologías audiovisuales no se están integrando apropiadamente. Los esquemas mentales preconcebidos de los profesores experimentados, ahora se están magnificando y, con ellos, sus errores. Sin caer en fatalismos, se trata de un problema grave: se incorpora la tecnología al aula, precisamente porque es necesario generar un cambio en la educación; pero como se cree que, por el hecho de adicionar dispositivos, se dará una innovación, de manera espontánea y natural, resulta entonces que el mismo profesorado queda atrapado en un bucle, en un laberinto, precisamente debido a que nunca nadie les hizo ver que debían buscar otro modo de hacerlo.

Para Argyris (1977, p. 120) no basta afirmar que la gente no se comporta de acuerdo con lo que considera sus teorías para la acción, porque eso no sería un hallazgo particularmente nuevo. Lo revelador de su argumento consiste en hacer notar que las personas ejecutivas no advierten esa inconsistencia entre lo que dicen 0 hacen abiertamente, y lo que en realidad les mueve a actuar. Aceptan el uso de la tecnología (teoría defendida), cuando en realidad no la integran (teoría en uso). O bien, usan la tecnología, pero no la integran. Argyris, coautor en varios escritos con Donald Schön, sintetiza algunas de estas investigaciones seminales en aprendizaje organizativo, en estudios incluyen observaciones y elaboraciones teóricas, que permitieron analizar los orígenes del comportamiento organizativo en ejecutivos y profesionales.

Argyris explica estos planteamientos en su artículo Teaching Smart People How To Learn (1991). Se trata de una especie de "doble discurso" que también se podría aplicar en docentes de personas ejecutivas, docentes listos, quienes creen que por usar la tecnología 
dentro del aula están integrándola, pero en realidad no lo hacen. En consecuencia, se debe a que no incorporan las capacidades de la tecnología, sino que sobre todo agudizan sus limitaciones dentro de la práctica docente. Aunque creen aplicar esquemas mentales nuevos, continúan usando los anteriores.

En tales casos, si no se comportan consistentemente con sus propias teorías, entonces podría concluirse que el modo de corregirlo es alterando su comportamiento. No obstante, según los estudios de Argyris al respecto, intentar cambiar el comportamiento no es suficiente y, de hecho, podría conducir a otro comportamiento transitorio y superficial. Por tanto, para lograr mayor coherencia entre lo que se dice y lo que se hace, no basta modificar las buenas o malas prácticas dentro del aula; sino que es necesario hacerlo mediante actividades reflexivas, y no sólo las ejecutivas. Se reafirma con esto, la dialéctica reflexiónacción del modo de aprendizaje de docentes propuesta por Kolb. Haber encontrado estos puntos de conexión permite dar paso a sugerir en qué consiste la integración de la tecnología.

\subsubsection{Integración de la tecnología}

Un vocabulario apropiado para entender en qué consiste la integración de la tecnología puede ser el elaborado por Gerardine DeSanctis y Marshall Poole (1994), y Anthony Giddens (1984). En estos autores se hace referencia a que las tecnologías habilitan (en inglés "enablements") y restringen (en inglés "constraints") los comportamientos. En el caso de tecnologías complejas, estas habilitaciones y restricciones interactúan con capacidades cognitivas específicas.

Por ejemplo, los profesionales jóvenes en radiología que poseían el conocimiento relevante de cómo operar los equipos de resonancia magnética e interpretar sus reportes, fueron habilitados por tecnología sofisticada para lograr diagnósticos más rápidos y precisos debido a un mayor detalle y claridad en las imágenes que usaron. De manera similar, el profesorado capaz de manejar con pericia las oportunidades que ofrece la tecnología, hará posible que la integración tecnológica se concrete dentro de un aula, y constituirse como expertos en la integración audiovisual. Esta capacidad quizá la desarrollen con mayor facilidad el profesorado joven, por ser más breve su trayectoria y, por tanto, contar con esquemas mentales menos arraigados.

Por otro lado, la restricción de comportamientos puede hacer referencia a la constricción planteada por la tecnología en forma de una mayor complejidad de 
funcionamiento. La reflexión permite que una actividad compleja se haga ver como sencilla, y eso es posible mediante la relación explícita de las conexiones mentales. De ahí que una restricción que ofrece la tecnología, como es el caso de la lectura de reportes - distinta a la lectura de placas de rayos $\mathrm{X}$ - impide que los médicos de mayor trayectoria la integren en su rutina diaria.

Esa misma incapacidad de gestionar las limitaciones de la tecnología es la que impide al profesorado de personas ejecutivas integrar la tecnología. Un recurso multimedia puede ser tan sofisticado como los avances tecnológicos lo permitan. Por tanto, la complejidad de manejar esos equipos no solamente estará asociada a la gestión técnica (conectar, interpretar, operar), sino al conocimiento pertinente para integrarlo dentro de un todo más complejo. La capacidad de manejar esas limitaciones de funcionamiento, son las que inhibirán o habilitarán la integración.

Resumiendo: por un lado, están las posibilidades y oportunidades de la tecnología (habilitadores); y de otro, las limitaciones y problemas de la tecnología (restricciones). Ambos componentes, habilitadores y restricciones, hacen referencia a un conocimiento especializado. En consecuencia, carecer del conocimiento pertinente impide integrar limitantes y oportunidades de la tecnología, motivo por el cual se hace un mal uso de ella.

Este mismo comportamiento puede inferirse en la educación ejecutiva. Profesorado experimentado, carentes del conocimiento pertinente para integrar las habilitaciones de la tecnología y gestionar apropiadamente sus restricciones, es lo que les va a impedir hacer un buen uso de ella. En cambio, si ese mismo profesorado -probablemente más joven- se ve en capacidad de integrar todas las habilitaciones tecnológicas y gestionar sus restricciones, entonces integrará la tecnología. En otras palabras, la integración no es sólo utilizar o involucrar la tecnología, sino integrarla dentro de un todo más complejo, que será posible gracias al ejercicio de la reflexión. Esto lleva a proponer que la integración de la tecnología es la forma en que las capacidades y restricciones de la tecnología están incorporadas en el ejercicio profesional ${ }^{4}$. Esta definición hace posible entender mejor en qué consisten los modelos de integración de la tecnología.

\footnotetext{
${ }^{14}$ En inglés la traducción sería la siguiente: “Technology integration is the way the technology's enablements and constraints are embedded into a practice".
} 


\section{Conclusiones}

Todo lo anterior plantea numerosos desafíos en el campo de la educación. Una manera de ejemplificarlo es refiriéndose a los cambios radicales que ha provocado el COVID-19 en las dinámicas mundiales de la docencia, incluyendo a las personas ejecutivas. La virtualización de la educación a raíz de la pandemia del Coronavirus ha sido un reto de innovación educativa a nivel global, porque el profesorado a nivel mundial ha tenido que dedicar numerosas horas a aprender nuevas tecnologías y a reformular la entrega de sus contenidos.

Al inicio de este ensayo científico se hizo notar que existe una marcada tendencia en las escuelas de negocios y en el sector corporativo, a incorporar el formato de educación mixta o híbrida; esto es, combinar la educación presencial con plataformas virtuales. Lo anterior implica que el profesorado debe transmitir, en la educación presencial, la misma cantidad de conocimiento, pero en menor cantidad de tiempo. Esto, lejos de indicar que la enseñanza cara a cara está perdiendo relevancia, enfatiza la necesidad de mejorar la experiencia de aprendizaje, con recursos multimedia o virtuales. De hecho, los mismos principios que aplican a la integración de la tecnología dentro del aula pueden ser llevados al campo de la virtualización de la enseñanza. Por ejemplo, se explicó que el profesorado de ejecutivos tiene un estilo de aprendizaje orientado a la ejecución y a la reflexión: eso tiene implicaciones en el uso de las plataformas tecnológicas, presenciales o virtuales, lo mismo que el rol de facilitador.

A lo largo de este documento también se propuso que el profesorado tiene la necesidad de aprender a integrar los recursos tecnológicos, a fin de optimizar las experiencias didácticas y lograr aprendizajes perdurables. Por ejemplo, la forzosa integración de la tecnología durante la pandemia, ha requerido más que nunca mecanismos personales de "feedback" para que el profesorado haga correcciones inmediatas y mejoras oportunas mientras imparte sus lecciones. Esa actividad de "feedback" es posible si, mientras enseña, se auto evalúa con sentido crítico sobre los posibles modos de optimizar su desempeño y el de sus aprendices: esa es una actitud reflexiva.

Ahora bien, en la literatura académica de negocios no se encuentran estudios ni teóricos, ni empíricos, sobre la integración de la tecnología en la educación de ejecutivos. Esta investigación ha abordado esa brecha desde tres áreas: el modo en que aprende el profesorado, la manera en que se integra la tecnología audiovisual, y los procesos de innovación educativa, como se verá a continuación. 
En primer lugar, el profesorado aprende basado en la experiencia. Las experiencias se almacenan en la memoria, entendida ésta como el proceso por el que se conservan los conocimientos y las habilidades para el futuro. La repetición continuada de ciertas conductas hace que se fijen algunos esquemas mentales en la mente, generando así un conocimiento tácito. Esos esquemas mentales afectan positiva o negativamente el modo de enfrentar situaciones futuras, también las inciertas.

Desafortunadamente durante la pandemia del SARS-COV-2, gran cantidad de docentes han intentado impartir la misma cantidad de contenidos a través de recursos tecnológicos. Incluso han procurado emular las mismas metodologías de enseñanza, sustituyendo el medio, pero nunca adaptando el contenido ni las estrategias didácticas. Esto tiene severas implicaciones en el campo cognitivo, porque puede llevar a niveles de saturación en los estudiantes, o incluso hasta desvirtuar el objetivo de aprendizaje. Tener claro lo que se ha planteado en páginas anteriores, posiblemente cambiaría el modo de enfrentar esta crisis. La batalla de la integración de la tecnología se gana si se optimiza el aprendizaje, no solamente al incrementar las métricas de accesibilidad al Internet o a plataformas virtuales.

En segundo lugar, el aprendizaje crea conocimiento transformando la experiencia. Está constituido por etapas de experimentación, reflexión, abstracción y observación. Dependiendo de la relación de las personas con su entorno, variará el modo en que aprenden. El modo en que aprende el profesorado es un balance entre la ejecución y una profunda capacidad de reflexión. Su modo de aprendizaje, también orientado a la acción, no facilita su auto-conciencia por reformular esos modelos mentales.

Las instituciones de educación superior no estaban preparadas para la integración de la tecnología que supuso esta pandemia. Las únicas instituciones que estaban preparadas para hacerlo eran las universidades virtuales. Por ejemplo, en la Universidad de Costa Rica se decidió postergar el inicio de las clases del primer ciclo, para dar tiempo al profesorado, al estudiantado y a la institución asimilar una demanda masiva de miles de estudiantes. Sería ilógico pensar que ese compás de espera podía resolverse con tecnología, sin más.

En docentes más y menos jóvenes supuso un esfuerzo extraordinario por optimizar la calidad de los cursos mediados por tecnologías de información. En otras palabras, no bastaba dar clases por tele presencia: se trataba de integrar la metodología, los contenidos y las personas a una plataforma tecnológica, y eso no se lograba de la noche a la mañana. Eso obedece a que, más que tiempo para cuestiones logísticas u operativas, la integración 
tecnológica requiere tiempo para una transformación de las creencias y hábitos de las personas, tanto docentes como estudiantes, pero particularmente de las personas más adultas e incluso expertas en su campo de enseñanza.

En tercer lugar, el profesorado suele usar los mismos esquemas mentales. Incluso el profesorado más experimentado usa el mismo abordaje metodológico al usar la pizarra y método del caso, con la tecnología o sin ella. Esa mentalidad de "mejora", y no de "transformación", es ocasionada por la falta de reflexión por parte de los profesores.

El desafío de la integración tecnológica durante la pandemia ha sido más patente en personas con mayor edad, precisamente porque tienen esquemas de trabajo mucho más arraigados que sus colegas más jóvenes. Intuitivamente, el profesorado recuerda las vivencias pasadas y las conecta con las presentes e incluso a posibles escenarios futuros. Paradójicamente, aunque es más fácil que el profesorado más joven use la tecnología, no necesariamente significa que la utilizará apropiadamente para fines didácticos. La predisposición a la tecnología facilita su uso, pero no su apropiada integración. La integración de la tecnología a la didáctica necesita de práctica, de ensayar y de cometer errores, de buscar modos de hacer más explícita la dinámica de aprender y desaprender.

Para terminar este ensayo, amerita añadir que una manera de cambiar los esquemas mentales es mediante actividades que promuevan la autoconciencia en medio de la acción docente, lo cual se facilita acudiendo a los modelos de integración de la tecnología, tales como el TPACK o el SAMR (Koehler and Mishra, 2009; Puentedura, 2010). Estos modelos de integración facilitan el modo de coordinar contenidos, tecnología, pedagogía y personas en una dinámica de enseñanza-aprendizaje. Para investigación futura, se recomienda explorar el modo en que funcionan estos modelos, y cómo a su vez activan la capacidad de reflexión del profesorado y del estudiantado mientras ejercen su oficio.

\section{Referencias}

AACSB International. (2015). Business School Technology Survey: Technology in Business Schools Roundtable (TBSr). Recuperado de https://www.aacsb.edu/accreditation/accredited-

schools?F_Accreditation=Business\&F_SchoolName=business+school+technology+survey

Aldunate, Roberto., and Nussbaum, Miguel. (2013). Teacher adoption of technology. Computers in Human Behavior, 29, 519-524.

Ambrose, Susan A (Ed.). (2010). How learning works: seven research-based principles for smart teaching (1st. ed.). Jossey-Bass. 
Argyris, Chris. (1977). Double loop learning in organizations. Harvard Business Review, 55(5), 115.

Argyris, Chris. (1991). Teaching Smart People How to Learn. Harvard Business Review, 69(3), 99-109.

Argyris, Chris., and Schön, Donald. (1996). Organizational learning II: theory, method, and practice. Reading: Addison-Wesley Publ.

Barley, Stephen R. (1986). Technology as an Occasion for Structuring: Evidence from Observations of CT Scanners and the Social Order of Radiology Departments. Administrative Science Quarterly, 31(1), 78-108.

Barley, Stephen R. (1990). The Alignment of Technology and Structure through Roles and Networks. Administrative Science Quarterly, 35(1), 61-103.

Brown, Malcolm., Mccormack, Mark., Reeves, Jamie., Brooks, D. Christopher., Grajek, Susan., Bali, Maha;... Horizon, Educause. (2020). 2020 EDUCAUSE Horizon Report ${ }^{{ }^{M} M}$ Teaching and Learning Edition. Washington, DC: EDUCAUSE.

Bryan, Alexander., Ashford-Rowe, Kevin., Barajas-Murphy, Noreen., Dobbin, Gregory., Knott, Jessica., McCormack, Mark ... Weber, Nicole. (2019). EDUCAUSE Horizon Report 2019 Higher Education Edition. Austin, Texas: EDUCAUSE.

Daudelin, Marilyn Wood. (1996). Learning from Experience Through Reflection. Organizational Dynamics, 24(3), 36-48.

De Déa Roglio, Karina. and Light, Gregory. (2009). Executive MBA Programs: The Development of the Reflective Executive. Academy of Management Learning $y$ Education, 8(2), 156-173.

DeSanctis, Gerardine. and Poole, Marshall. (1994). Capturing the Complexity in Advanced Technology Use: Adaptive Structuration Theory. Organization Science, 5(2), 121-147.

Dewey, John. (1938). Experience and education: the 60th anniversary edition. West Lafayette, Indiana: Kappa Delta Pi, 1998.

Ertmer, Peggy A., Ottenbreit-Leftwich, Anne T., Sadik, Olgun., Sendurur, Emine. and Sendurur, Polat. (2012). Teacher beliefs and technology integration practices: A critical relationship. Computers and Education, 59(2). Doi https://doi.org/10.1016/j.compedu.2012.02.001

Ertmer, Peggy A. (1999). Addressing first- and second-order barriers to change: Strategies for technology integration. Educational Technology Research and Development, 47(4), 47-61.

Ertmer, Peggy A. (2005). Teacher Pedagogical Beliefs: The Final Frontier in Our Quest for Technology Integration? Educational Technology Research and Development VO - 53, (4), 25. 
Giddens, Anthony. (1984). The constitution of society: outline of the theory of structuration. Berkeley: University of California Press.

Goh, Joshua O. and Park, Denise C. (2009). Neuroplasticity and cognitive aging: The scaffolding theory of aging and cognition. Restorative Neurology and Neuroscience, 27(5), 391-403.

Graham, Sandra. and Nastasi, Bonnie. (2015). Top 20 principles from psychology for preK12 teaching and learning. Washington DC: American Phychological Association.

Henry, George William. (2009). An historical analysis of the development of thinking in the principal writings of Malcolm Knowles (PhD Thesis). Queensland University of Technology, Brisbane, Australia.

lucu, Romiţă B., and Marin, Elena. (2014). Authentic Learning in Adult Education. Procedia Social and Behavioral Sciences, 142, 410-415.

Johnson, Roger T., and Johnson, David W. (2008). Active Learning: Cooperation in the Classroom. The Annual Report of Educational Psychology in Japan. Recuperado de https://www.researchgate.net/publication/234568124_Active_Learning_Cooperation_in _the_College_Classroom

Knowles, Malcolm S. (1980). The Modern Practice of Adult Education; Andragogy versus Pedagogy: revised and updated. New York: Cambridge.

Koehler, Matthew J. and Mishra, Punya. (2009). What Is Technological Pedagogical Content Knowledge (TPACK)? Contemporary Issues in Technology and Teacher Education, 9(1), 60-70.

Kolb, Alice Y. and Kolb, David A. (2011a). Experiential Learning Theory: A Dynamic, Holistic Approach to Management Learning, Education and Development. In The SAGE Handbook of Management Learning, Education and Development (pp. 42-68). Recuperado de https://www.researchgate.net/publication/267974468_Experiential_Learning_Theory_A_Dynami c_Holistic_Approach_to_Management_Learning_Education_and_Development

Kolb, Alice Y. and Kolb, David A. (2011b). The Kolb Learning Style Inventory 4.0: Guide to Theory, Psychometrics, Research y Applications. Boston, MA: Hay Resources Direct.

Kolb, Alice Y. and Kolb, David Allen. (2005). Learning Styles and Learning Spaces: Enhancing Experiential Learning in Higher Education. Academy of Management Learning y Education, 4(2), 193-212.

Kolb, David Allen. (1984). Experiential learning: experience as the source of learning and development. New Jersey: Prentice-Hall.

Linkedln. (2019). 2019 Workplace Learning Report. Learning Solutions. Recuperado de https://learning.linkedin.com/content/dam/me/business/en-us/amp/learningsolutions/images/workplace-learning-report-2019/pdf/workplace-learning-report2019.pdf 
Meyers, Chet;and Jones, Thomas B. (1993). Promoting Active Learning: Strategies for the College Classroom. The JosseyBass higher and adult education series. Jossey Bass Higher and Adult Education Series.

Nespor, Jan K. (1987). The Role of Beliefs in the Practice of Teaching: Final Report of the Teacher Beliefs Study. Journal of Curriculum Studies, 19(4), 317-328.

Pajares, M. Frank. (1992). Teachers' Beliefs and Educational Research: Cleaning Up a Messy Construct. Review of Educational Research, 62(3), 307-332.

Polanyi, Michael. (1966). The tacit dimension. Garden City, N.Y.: Doubleday y Company.

Puentedura, Ruben. (2010). SAMR and TPCK: intro to advanced practice. In SAMR, TPCK, and Educational Technology: Three Presentations (p. 48). Göteborg and Stockholm. Retrieved from http://www.hippasus.com/rrpweblog/archives/000049.html

Rachal, John R. (2002). Andragogy's Detectives: A Critique of the Present and a Proposal for the Future. Adult Education Quarterly, 52(3), 210-227.

Schön, Donald. (1983). The reflective practitioner: how professionals think in action. United States of America: Basic Books.

Shulman, Lee S. (1986). Those who understand: knowledge growth in teaching. Educational Researcher, 15(2), 4-14.

Wiggins, Grant. (2011). A true test: Toward more authentic and equitable assessment. Phi Delta Kappan, 92(7), 81-93. 


\section{Revista indizada en}
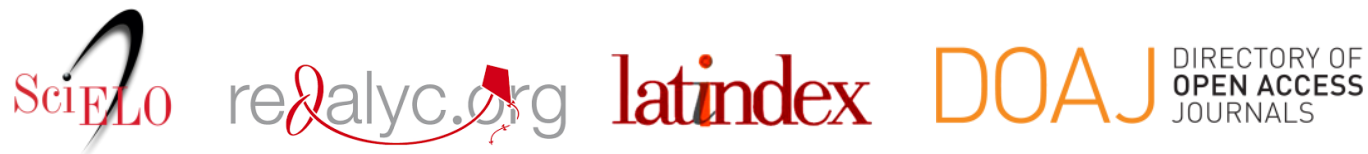

Distribuida en las bases de datos:
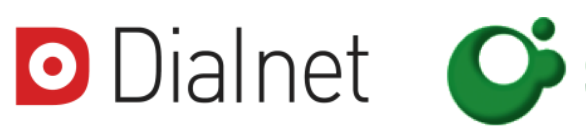
SHERPA/RøMEO

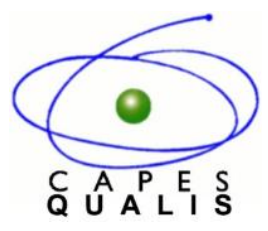

MIAR 